\title{
Otitis Media with Effusion: Comparative Effectiveness of Treatments
}

\author{
Dr.Karuna Nooni ${ }^{1}$ Dr.G.Sreekanth ${ }^{2}$, \\ ${ }^{1}$ Assistant Professor Of Otorhinolaryngology, Osmania General Hospital,Hyderabad,India \\ ${ }^{2}$ Assistant Professor Of Otorhinolaryngology, Gandhi Medical College,Hyderabad,India
}

\begin{abstract}
:
Background: otitis media with effusion(OME) is defined as a collection of fluid in the middle ear without signs or symptoms of acute ear infection.OME has several potential causes. The presence of fluid in the middle ear decreases tympanic membrane and middle ear function, leading to decreased hearing and learning disabilities. Hence early detection and proper intervention is necessary.

Materials And Methods: 30 Patients of paediatric age group(0-13yrs.) were primarily selected from ENT out-patient department, Gandhi hospital and Osmania General Hospital, from June 2013 to December 2015 , on the basis of suggestive symptoms persisting for 4 weeks to 4 months period of time, after medical management.

Results: Coming to the comparison of treatment modalities, it is observed that the more beneficial group was group B (Grommet insertion with Adenoidectomy). This could be made out by comparing the closure of percentage of air-bone gap before and after the treatment.

Conclusion: adjuvant adenoidectomy at the time of initial insertion of grommets decreased the risks of reinsertion and re-admission for conditions related Chronic otitis media with effusion.

Keywords: $\quad$ Otitis Media With Effusion(OME),Grommet,Adenoidectomy,Pure tone audiometry, Tympanometry .Secretory Otitis Media.
\end{abstract}

\section{Introduction}

Otitis media with effusion is one of the commonest medical problem in young children. The Otitis media with effusion is insidious in onset, usually run a long course. The clinical resentation varies accordingly. olitzer (1869)described Otitis media catarrhalis and recognized secretory and adhesive forms of the disease in his classic book "The diseases of the ear" in 1902. .The therapy he advocated consists of insufflations of air and paracentesis of middle ear, which were intended to equalize the atmospheric pressure on both the sides of the tympanic membrane. Both ventilation and drainage of the middle ear have remained the basic principle in the management of middle ear fluids to date.

Middle ear fluid received little attention from then until the time of the second world war. The condition occurs in childhood as hearing loss, otalgia, and an educational or behavioral problems. In the younger children it may present as speech and language delay(Maw R, Wilks J, Harvey I, et al. )$^{1}$. Such cases need early detection and proper treatment Antibiotics do not have much role in the management of Otitis media with effusion. The usual surgical treatment is Myringotomy with grommet insertion ${ }^{2}$. There is debate about the usefulness of adjuvant Adenoidectomy and adenotonsillectomy ${ }^{3}$. procedures in the outcome of the procedure of insertion of tympanostomy tubes and sequelae of the disease. In current study we examined the effects of the adjuvant procedures on the rates of recurrence and re-insertion of grommets, hearing improvement and sequelae of the disease.

\section{Objectives}

1)To compare the efficacy of different modalities of surgical treatment designed for this condition, and

2)Analysis of the results statistically.

\section{Materials and Methods}

Materials: Nineteen boys and eleven girls ranging in age from 0 to 13 made up the patient population. Each of the 30 cases fit into the specifications of the study. A pure conduction type hearing loss and type-B flat tympanogram with no acoustic reflex were present preoperatively. Among these 30 cases, 15 cases were subjected to grommet insertion and another 15 cases were subjected to adenoidectomy along with grommet insertion. All the patients had enlarged adenoids in

DOI: $10.9790 / 0853-150722934 \quad$ www.iosrjournals.org $\quad 29 \mid$ Page


relation to the size of the nasopharyngeal space. The fluid in the middle ear of each individual is similar in quality(mucoid) and quantity.

With the present study the following observations and conclusions were deduced. The present study of clinical profile in Otitis media with effusion was studied in ENT department, Gandhi medical college, and osmania general hospital.

30 Patients of paediatric age group(0-13yrs.) were primarily selected from ENT out-patient department, Gandhi hospital and Osmania General Hospital from June 2014 to December2015, on the basis of suggestive symptoms persisting for 4 weeks to 4 months period of time, after medical management. Then they underwent thorough ENT examination. The patients were examined with otoscopy, otoendoscopy, diagnostic nasal endoscope to assess the size of adenoids and operating microscope.

Pure tone audiometry was done to assess the degree of conductive haring loss. The diagnosis was further confirm by Tympanometry(Glasgow studies by Dempster and Mackenzie(1991), ${ }^{4}$. Only type-B tympanogram was considered as diagnostic of otitis media with effusion in this study.

All the cases were subjected to radiological examination i.e x-ray nasopharynx to assess the adenoid status.

After confirmation of the diagnosis, the patients were subjected to two different treatment modalities like A) Grommet insertion and B) Grommet insertion with adjuvant Adenoidectomy.

\section{Methods}

The Adenoidectomy was done under general anaesthesia. In most of the cases myringotomies are done in anterosuperior quadrant, and for those cases with narrow canal it was done in anteroinferior quadrant of tympanic membrane $e^{5}$. Following evacuation of middle ear fluid, grommet is inserted.

All patients have been reviewed otoscopically and audiometrically after one month and successively at three months, six months, nine months postoperatively. The parents opinion was taken regarding the value and morbidity of the procedures, especially relative

\section{Observation and results} made.

In the present study of thirty cases of chronic OME the following observations were

Age incidence: According to Telle and Kelin the incidence of Secretory otitis media is much high in children in the age group of three to five years, but in our present study the incidence was high in the age group between four to seven years.

Table I. The age incidence of Secretory otitis media

\begin{tabular}{|c|c|c|}
\hline $\begin{array}{c}\text { AGE GROUP } \\
\text { IN YEARS }\end{array}$ & NO. OF CASES & PERCENT \\
\hline $0-3$ & 5 & 16.67 \\
\hline $4-7$ & 16 & 53.33 \\
\hline $8-10$ & 7 & 23.33 \\
\hline $11-13$ & 2 & 6.67 \\
\hline TOTAL & 30 & 100 \\
\hline
\end{tabular}

Figure:

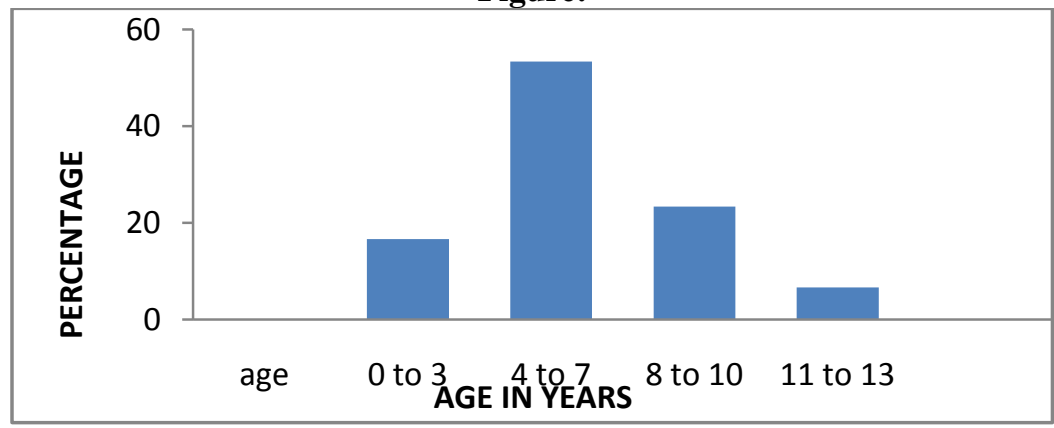

Sex incidence: It was noted in our study that there was male preponderance. This was in the ratio of 1:2 (female:male) as shown in table II. The study made by Tos and Stangerup in 1985 has also shown the male preponderance. 
Table II: sex incidence:

\begin{tabular}{|c|c|c|}
\hline Sex & No. of cases & Percent \\
\hline Male & 19 & 63.33 \\
\hline Female & 11 & 36.67 \\
\hline Total & 30 & 100 \\
\hline
\end{tabular}

Figure:2

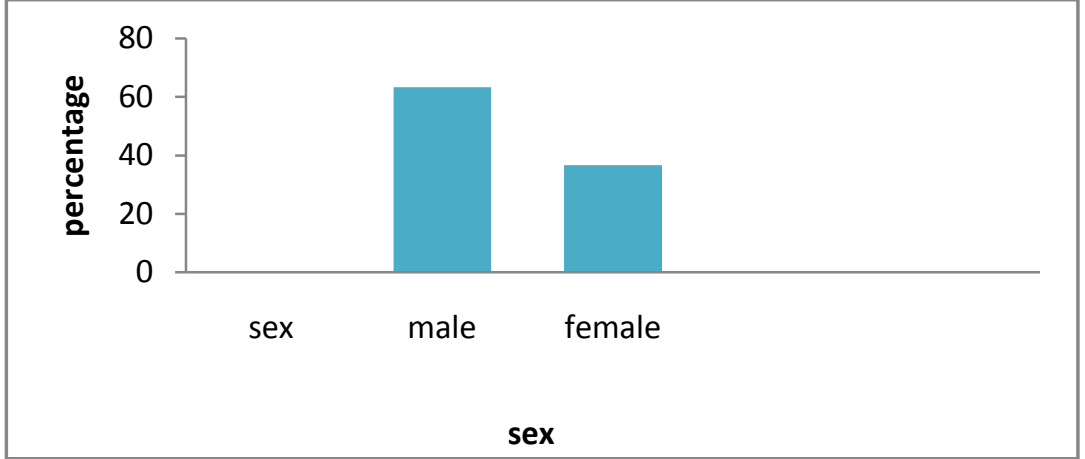

Signs: On otoscopic examination the predominant signs ${ }^{6}$ were Bulging of tympanic membrane without congestion(due to recurrent antibiotics), dull \& amber colored tympanic membrane and prominence of handle of malleus and short process of incus(due to mild retraction).

Table III: The percentage of signs.

\begin{tabular}{|l|c|c|}
\hline \multicolumn{1}{|c|}{ Signs } & No. of cases & Percent \\
\hline Dull, lusterless T.M & 7 & 23.33 \\
\hline Retraction & 2 & 6.67 \\
\hline Bulging T.M without congestion & 16 & 53.33 \\
\hline Air bubbles & 3 & 10 \\
\hline Air fluid level & 2 & 6.67 \\
\hline TOTAL & 30 & 100 \\
\hline
\end{tabular}

As per this table the predominant signs were Bulging timpanic membrane without congestion in $53.33 \%$ and Dull \& lusterless T.M in $23.33 \%$ of cases.

Figure:3

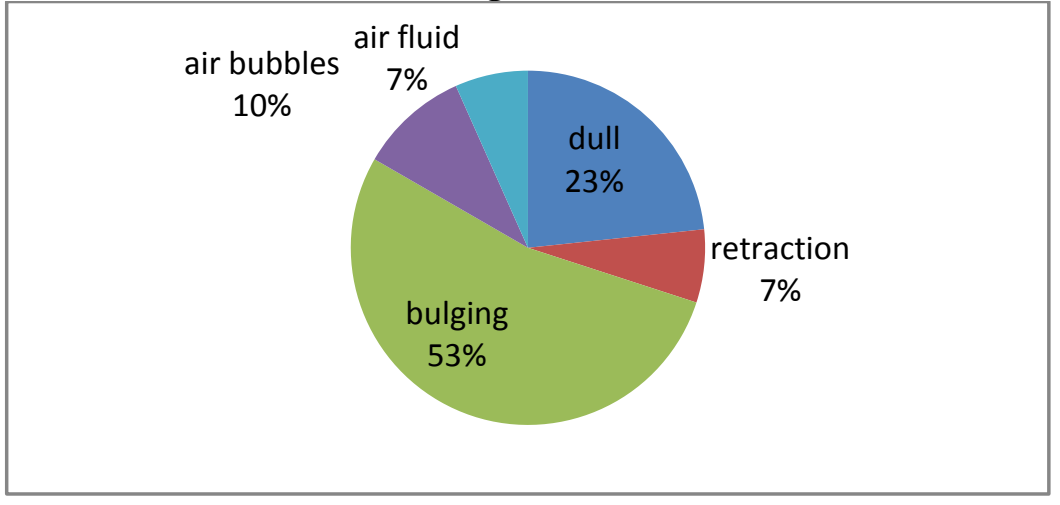

Symptoms: The various symptoms with which these thirty patients were presented are shown in the

Table IV.

\begin{tabular}{|l|c|c|}
\hline \multicolumn{1}{|c|}{ Symptoms } & No. Of cases & Percent \\
\hline Fullness in the ear & 10 & 33.33 \\
\hline Hard of hearing & 12 & 40 \\
\hline Tinnitus & 1 & 3.33 \\
\hline Bubbling & 2 & 6.67 \\
\hline Delayed Speech & 5 & 16.67 \\
\hline TOTAL & 30 & 100 \\
\hline
\end{tabular}


As per this table the predominant symptoms were fullness of the ear in $33.33 \%$ and hard of hearing in $40 \%$ of cases.

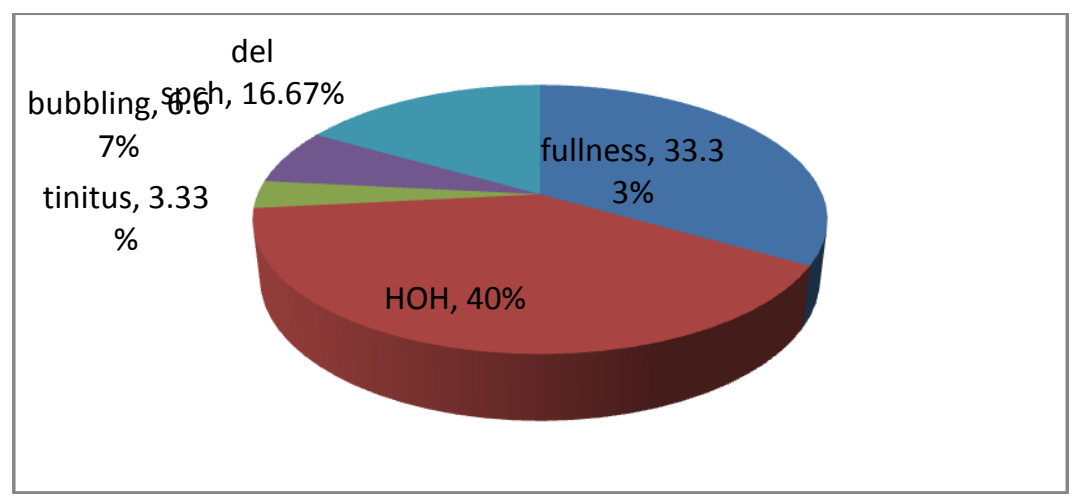

These thirty cases of chronic OME under this study were treated as two different groups A\&B.Group A :Grommet insertion.

Group B: Adenoidectomy and Grommet insertion.

\begin{tabular}{|c|c|c|c|c|c|}
\hline \multirow[t]{2}{*}{ Groups } & \multirow[t]{2}{*}{ Treatment } & \multirow[t]{2}{*}{ No.of cases } & \multicolumn{2}{|c|}{ AB-gap } & \multirow[t]{2}{*}{$\begin{array}{l}\text { \%of provement } \\
\text { in AB-gap }\end{array}$} \\
\hline & & & Before & After & \\
\hline A & Grommet insertion & 15 & 29.6 & 16.0 & $43.33 \%$ \\
\hline B & $\begin{array}{l}\text { Grommet and } \\
\text { Adenoidectomy }\end{array}$ & 15 & 31.27 & 11.40 & $64.30 \%$ \\
\hline & Total & 30 & & & \\
\hline
\end{tabular}

Statistical Analysis The Improvement In The Percentage Of Ab Gap Of 15 Children In Group-A Compared With 15 Children In Group-B, By Using Student's T-Test.

\section{Student's T-Test: Results}

The results of an unpaired t-test performed $\mathrm{t}=3.70$

standed deviation $=15.6$

degrees of freedom $=28$ The probability of this result, assuming the null hypothesis, is 0.0009 .This p-value is considered to be statistically significant.

Group A: Number of items $=15$

51.052 .056 .058 .058 .060 .060 .065 .067 .067 .071 .072 .073 .076 .079 .0

Mean $=64.3$

95\% confidence interval for Mean: 56.08 thru 72.58

Standard Deviation $=8.71$

$\mathrm{Hi}=79 \mathrm{Low}=51 \quad$ Median $=65.0$

Average Absolute Deviation from Median = 7.33

Group B: Number of items $=15$

9.0016 .016 .020 .034 .045 .046 .048 .050 .052 .053 .053 .062 .067 .078 .0

Mean $=43.3$

95\% confidence interval for Mean: 35.02 thru 51.52

Standard Deviation $=20.3 \mathrm{Hi}=78.0$ Low $=9.00$

Median $=48.0$

Average Absolute Deviation from Median = 15.3

\section{Discussion}

Chronic OME is commonest cause of hearing difficulty encountered by an Otologist. It is characterized by the accumulation of fluid in the middle ear cavity, due to alterations in mucociliary system within middle ear, Eustachian tube and inadequate treatment. The Otologists all over the world have attempted to solve the problems encountered in the treatment of Chronic OME and provided the best treatment(hearing improvement). 
Age incidence: It was observed that the commonest age group suffering from OME were in the age group of 4-7 years. This high age at presentation indicates the late presentation of patients to hospital due to their ignorance, poverty, low socioeconomic conditions and lack of regular screening in the school children as they do in the western countries.

Sex incidence: In our study it is observed that the secretory otitis media is common in male children. This may be due to male preponderance of childhood upper respiratory infections, boys have less well pneumatised air cell system which may be a consequence of tubal dysfunction and more marked middle ear pathology, supporting the environmental rather than the hereditary theory of mastoid pneumatisation.

Socio-economic status: This fact is clearly reflected in the present study where most of the cases(70\%) belong to low socioeconomic group, $16 \%$ belongs to middle class and the remaining $14 \%$ belongs to upper class. This poor socioeconomic status may play a role in the etiology of the disease directly as well as indirectly.

Symptomatology: The common symptoms in order of frequency were Hard of hearing40\%, Fullness of tympanic membrane 33.33\%, Delayed speech16.67\%, Bubbling sound6.67\% Tinnitus3.33\%.

In the present study the symptom fullness is explained by the presence of middle ear fluid, found on examination with otoscope. Hard of hearing is explained by parents, with tuning fork tests and pure tonecaudiometry, which has shown $20-60 \mathrm{~dB}$ of conductive hearing loss in our study. Tinnitus may be due to pressure effect in middle ear cavity.

Studies by Schilder zielhais \& Venden broek 1993 has shown a mean of $20 \mathrm{~dB}$ conductive hearing loss. In Glasgow studies by Dempster \& Mackenzie 1991 has shown a mean of $26 \mathrm{~dB}$ conductive hearing loss.

Clinical findings: Signs in order of frequency were Bulging tympanic membrane without congestion due to prior usage of antibiotics 53.33\%, Dull ,lusterless tympanic membrane23.33\%, Air bubbles 10\%, Retraction6.67\% and Air fluid level 6.67\%.

All these findings were confirmed by otoscopic, otoendoscopic and operating microscopic examination. Mobility of tympanic membrane is assessed by Seigles pneumatic speculum.

Management: These 30 cases of secretory otitis media under study were treated as two groups. Grour A and group B.

GroupA: Grommet insertion .

GroupB: Grommet insertion with adjuvant Adenoidectomy.

Follow up:

During follow up the patients were asked to attened the out patient department for the following.

1.To see the grommets position 2.To aspirate the secretions and

3.To see the status of tympanic membrane. $\quad$ 4.To assess the hearing improvement.

The period of follow up is- initially weekly once for one month, there after at 3 months, 6 months and 9 months. Few patients failed to attened regular followup.

- Of the 30 children, 15 cases received adenoidectomy with grommet, another 15 cases received only grommet insertion as their first surgical treatment for otitis media with effusion.

- Of the group that received grommet insertion ,6 cases presented with ear discharge at second week of follow up. Among these, extrusion of grommets occurred in 3 cases $(2$ cases are due to infection, 1 case is due to unknown etiology), but during further follow-ups the above said 2 cases progressed to chronic suppurative otitis media and in other case re- insertion of grommet was done. Remaining 3 cases showed complete recovery from discharge at 3 months follow-up visit.

-Of the group that received grommet insertion with adenoidectomy, 4 cases had ear discharge during their first follow- up visit, which subsided by medication(antibiotics\&antihistaminics).

- Of those $16.66 \%$ cases that presented with delayed speech, all cases showed significant improvement of speech.But $50 \%$ of improvement in air bone gap is observed in group A (grommetinsertion) and 53\% of improvement in air-bone gap in groupB (adjuvant adenoidectomy).

- Finding that the proportion of parents who expressed satisfaction was higher among those whose children had adjuvant adenoidectomy than in those whose children had only grommet insertion.

Our study has, however, investigated the sensitivity and specificity of pre-operative findings in predicting the outcome of surgery despite, the uncertainties surrounding the level of objectivity of audiometry. This single measure appears to be useful predictor of outcome. 
In our study it was observed that the improvement in the percentage of air bone gap is $43.33 \%$ in group A(grommet insertion), and $64.30 \%$ in group B (grommet insertion with adenoidectomy).

\begin{tabular}{|c|c|}
\hline \multicolumn{2}{|c|}{ BIL.GROMMET INSERTION } \\
\hline & Mean(SD)hearing thresholds \\
\hline Before surgery & $30.90 \quad(8.98)$ \\
\hline After surgery & $13.06 \quad(9.49)$ \\
\hline \multicolumn{2}{|c|}{ ADENOIDECTOMY WITH GROMMET INSERTION } \\
\hline Before surgery & $31.51 \quad(8.58)$ \\
\hline After surgery & $14.12 \quad(9.00)$ \\
\hline
\end{tabular}

The data from our present study, and the data collected from the work done by Richard Maw, Rachel Bawden in 1993, showed a significant improvement in hearing thresholds with the group that has subjected to Adenoidectomy with Grommet insertion when compared to Grommet insertion alone.

\section{Summary And Conclusion}

Patients attending ENT outpatient department, Gandhi hospital and Osmania General Hospital with the complaints of hard of hearing and fullness in ears were examined for the presence of Otitis media with effusion and 30 cases were identified and studied in detail.

The age incidence shows preponderance to 4-7 years. This could be due to late presentation of patients and lack of pre-school screening in our country.

Sex preponderance was found towards males. This may be due to male preponderance of childhood upper respiratory infections. Boys have less well pneumatised air cell system which may be a consequence of tubal dysfunction and more marked middle ear pathology, supporting the Environmental rather than the Hereditary theory of mastoid pneumatisation (Accordig to study made by TOS\&STANGERUP).

Coming to the comparison of treatment modalities, it is observed that the more beneficial group was group B (Grommet insertion with Adenoidectomy). This could be made out by comparing the closure of percentage of air-bone gap before and after the treatment.

In summary adjuvant adenoidectomy at the time of initial insertion of grommets decreased the risks of reinsertion and re-admission for conditions related Chronic secretory otitis media.

So it is concluded that from our present study:

Otitis media with effusion can be diagnosed accurately with clinical examination, and through investigations (otoscopy, operating microscopy and tympanometry).

The present study as shown male preponderance and increased incidence in the age group between $4-7$ years.

In this study it is observed that the combined Adenoidectomy with grommet insertion being better than the Grommet insertion alone in the management of Chronic secretory otitis media.

\section{References}

[1]. Maw R, Wilks J, Harvey I, et al. Early surgery compared with watchful waiting for glue ear and effect on language development in preschool children: a randomised trial. Lancet. 1999 Mar 20;353(9157):960-3. PMID: 10459904

[2]. Mandel EM, Rockette HE, Bluestone CD, et al. Myringotomy with and without tympanostomy tubes for chronic otitis media with effusion. Arch Otolaryngol Head Neck Surg. 1989 Oct:115(10):1217-24. PMID: 2789777

[3]. Austin DF. Adenotonsillectomy in the treatment of secretory otitis media. Ear Nose Throat J. 1994 Jun;73(6):367-9, 73-4. PMID: 8076535.

Williamson IG, Dunleavey J, Bain J, et al. The incidence and prevalence of abnormal tympanograms in four South West Hampshire infant J Laryngol Otol. 1994 Nov;108(11):930-4. 5

[4]. Williamson IG, Dunleavey J, Bain J, et al. The incidence and prevalence of abnormal tympanograms in four South West Hampshire infant J Laryngol Otol. 1994 Nov;108(11):930-4. 5

[5]. Hern JD, Jonathan DA. Insertion of ventilation tubes: does the site matter? Clin Otolaryngol Allied Sci. 1999 Sep;24(5):424-5. PMID: 10542923 Williamson I. Otitis media with effusion in children. Clinical Evidence. 2011;pii: 0502. PMID: 21477396.

RichardMaw,RachelBawden(BMJ1993;306:756-60). TAB

[6]. Glasgow studies by Dempster and Mackenzie(1991),

[7]. Lin J, Caye-Thomasen P, Tono T, et al. Mucin production and mucous cell metaplasia in otitis media. Int J Otolaryngol. 2012;2012:745325. PMID: 22685463.

Macknin ML, Jones PK. Oral dexamethasone for treatment of persistent middle ear effusion. Pediatrics. 1985 Feb;75(2):329-35. PMID: 4038553

Gates GA, Avery CA, Prihoda TJ. Effect of adenoidectomy upon children with chronic otitis media with effusion. Laryngoscope. 1988 Jan;98(1):58-63. PMID: 3336263 